given them. This is patently not true. The details of the multiple risk factor intervention trial show that hydrochlorothiazide (the diuretic used long term in the Finnish study) was stopped because of an adverse effect on mortality. In the Finnish study the overall use of antihypertensive drugs in terms of patient exposure was far greater than exposure to hypolipidaemic drugs: what is sauce for the goose is sauce for the gander.

It is important that the correct lessons are learn from the Finnish study about the prevention of coronary heart disease. ${ }^{5}$ We believe that readers have been done a disservice by Oliver's editorial.

M F RYAN

A MORAN

A F JONES

East Birmingham Hospital,

Birmingham B9 5ST

Oliver MF. Doubts about preventing coronary heart disease. BMF 1992;304:393-4. (15 February.)

2 Strandberg TE, Salomaa VV, Naukkarinen VA, Vanhanen HT, Sarna SJ, Miettinen TA. Long term mortality after 5 year multifactorial primary prevention of cardiovascular diseases in middle aged men. FAMA 1991;266:1225-9.

3 Miettinen TA, Jussi $\mathrm{K}$, Huttunen MD, Naukkarinen $\mathrm{V}$ Strand $T$, Malila $S$, et al. Multifacos Strandberg T, Mattila S, et al. Multifactorial primary prevention of cardiovascular

4 Multiple Risk Factor Intervention Trial Research Group. Mortality after 10.5 years for hypertensive participants in the multiple 990;82:1616-27.

5 Durrington PN, Bhatnagar D. Wrong lesson from Finnish trial of cardiovascular prevention. Lancet 1992;339:488.

SIR, - I wish to take issue with Michael F Oliver's suggestion that a moratorium on the use of cholesterol lowering drugs goes too far as it ignores the impressive reduction in non-fatal myocardial infarction reported in several trials. He states that the use of these drugs should be confined to high risk middle aged men.

An often overlooked aspect of these trials is exemplified by the Helsinki heart study using the drug gemfibrozil. ${ }^{2}$ Although an impressive percentage reduction in non-fatal myocardia infarction was seen in this trial, the absolute numbers who benefited were small compared with the size of the intervention cohort. In other words, even in this high risk group the chances of having a myocardial infarction were small over the five year duration of the study. As a result, large numbers of patients need to be treated without the prospect of benefit yet with all the disadvantages that drug treatment involves.

Until greater benefit can be assured or we can identify more precisely the characteristics of the subgroups in whom myocardial infarction was prevented, a moratorium is appropriate. Furthermore, given the poor results to date, well informed consumers would prefer to take their chances with the risk factors.

EUGENE A RYBINSKI

Burncross Surgery,

Sheffield S30 4RN

1 Oliver MF. Doubts about preventing coronary heart disease. $B M 7$ 1992;304:393-4. (15 February.)

2 Frick MH, Elo O, Haapa K, Heinonen OP, Heinsalmi P, Helo P, et al. Helsinki heart study: primary prevention trial with gemfibrozil in middle-aged men with dyslipidemia. N Engl f Med 1987;317:1237-45.

SIR, - "Too little too late" is the real subtle message in Michael F Oliver's editorial on the success of present efforts to prevent coronary heart disease. Despite adverse reports on total mortality in some reviews ${ }^{23}$ benefits have been shown in studies in which tight control of diet and drug treatment was maintained $^{+}$and in which there was rigorous intervention with regard to risk factors and diets were stricter than those recommended by most national bodies.

There is sense in exercising caution and dis- crimination in prescribing lipid lowering drugs. Diet should be the mainstay of managing all lipidaemias. Davey Smith and Pekkanen's paper reviewing the use of lipid lowering drugs, however, is unnecessarily alarmist. ${ }^{6}$ The authors have played down the benefits of treatment and produced a review that sounds superficially biased. The media have taken this at face value, and some broadcasts have served to discourage those who least need discouragement. A patient attending one lipid clinic was overheard saying, "On the telly they said the British Medical Magazine writes it's not worth bothering with all this health stuff."

South Tyneside district has a population with high morbidity and mortality from coronary heart disease. We consider that we should be working harder and earlier to reduce risk factors for the disease. In this health district, as in many others, health professionals, including general practitioners, have expended considerable effort on promoting healthy lifestyles and offering the population an assessment of risk factor, including cholesterol testing. Prevention of coronary heart disease is affected by the severity of existing atherosclerosis, and in South Tyneside a multidisciplinary working party has drawn up guidelines advocating a coronary heart disease prevention programme directed not just at middle aged men but at all subjects aged 20-65.

In the first stage of the programme we are assessing groups at highest risk, including those with a family history of coronary heart disease or a family history or signs of lipidaemia, diabetic patients, hypertensive patients needing treatment, and those with symptoms of ischaemic vessel disease. We have estimated that there are at least 36000 subjects in this high risk group aged 20-65 in South Tyneside, basing our calculations on methods used in the OXCHECK study. ${ }^{8}$ In this group the incidence of severe hypercholesterolaemia (cholesterol concentration $>8.0 \mathrm{mmol} / \mathrm{l}$ ) will be higher than the national average. All hypercholesterolaemic subjects are managed by diet, but those at particularly high risk who would benefit in the long term from a reduction in risk are also offered lipid lowering drugs

We hope that this enterprise will prevent some people in this section of the population from developing coronary heart disease.

A I POLANSKA

South Tyneside District Hospital,

South Shields,

Tyne and Wear NE34 OPL

1 Oliver MF. Doubts about preventing coronary heart disease. $B M$ f 1992;304:393-4. (15 February.)

2 Committee of Principal Investigators. A co-operative trial in the primary prevention of ischaemic heart disease using clofibrate. Br Heart f 1978;40: 1069-118

3 Holme I. An analysis of randomised trials evaluating the effect of cholesterol reduction on total mortality and coronary heart disease incidence. Circulation 1990;82:11916-24.

4 Lipid Research Clinics Program. The Lipid Research Clinics coronary primary prevention trial results. I. Reduction in incidence of

Hjermann I. The Oslo study: some trial results. Atherosclerosis Revieaus 1990;21:103-8.

6 Davey Smith G, Pekkanen J. Should there be a moratorium on the use of cholesterol lowering drugs? BMF 1992;304:431-4. (15 February.)

7 Multidisciplinary Working Group. Risk factor assessmen in primary health care: the report and recommendations of a multidisciplinary working group in south Tyneside. South Shields: South Tyneside Health Authority, 1991

8 Imperial Cancer Research Fund OXCHECK Study Group. Prevalence of risk factors for heart disease in OXCHECK trial: implications for screening in primary health care. $B M \mathcal{J}$ 1991;302:1057-60

SIR, - It is established that high blood cholesterol concentration, high blood pressure, and cigarette smoking are the main modifiable risk factors for coronary heart disease. Having read George Davey Smith and John Pekkanen's request for a moratorium on cholesterol lowering drugs ${ }^{1}$ and Michael F Oliver's accompanying editorial ${ }^{2}$ think it important that patients requiring treatment are not ignored.
Davey Smith and Pekkanen do not provide a sufficient review, choosing to look at only a third of relevant studies. ' One quoted Finnish study started 18 years ago, achieved a modest reduction in cholesterol concentration of $6.5 \%$ in five years, used some drugs that may worsen lipid profiles, and was in reality largely a failure of intervention rather than outcome. ${ }^{3}$ To suggest that increased all cause mortality in the 10 years after the study may have been due to small changes in cholesterol concentration during the study but was probably not due to hypertension or its treatment is disingenuous.

The question is raised of total mortality not having been reduced, but consideration of all trials together does show such a trend. No individual trials, however, have been designed to answer this question, and they would have to be much larger (of the order of 25000 subjects for five years). Trends towards increased deaths from violence are seen as secondary end points in several studies. Though they should not be ignored, they are also not a reason to ignore the treatment needs of people at higher risk of premature coronary heart disease.

Davey Smith and Pekkanen suggest that general use of lipid lowering drugs should not occur and that current use is too high, but their figures show that $0 \cdot 12 \%$ of the population are treated. ${ }^{1}$ One of the severe inherited single gene hyperlipidaemias, familial hypercholesterolaemia, occurs in $0.2 \%$ of the population, and most patients with this require treatment. Patients with coronary heart disease who have hypercholesterolaemia have shown benefit from active lipid lowering treatment. Patients with multiple risk factors who are at particular risk of premature coronary heart disease also require treatment and intervention for the multiple factors. In a minority at highest risk, if non-pharmacological measures are ineffective or insufficient to lower blood pressure and lipids drug treatment will be appropriate.

Likely benefits have to be weighed against potential disadvantages by economic and other analyses, such as in the Standing Medical Advisory Committee's report on cholesterol testing. ${ }^{4} \mathrm{~A}$ considerable disservice will have been done to prevention of coronary heart disease in the United Kingdom, and to a proportion of patients at highest risk of premature disease, if too extreme a view is taken.

Royal United Hospital,

J P D RECKLESS

Bath BAl 3NG

I Davey Smith G, Pekkanen J. Should there be a moratorium on the use of cholesterol lowering drugs? BMF 1992;304:431-4 (15 February.)

2 Oliver MF. Doubts about preventing coronary heart disease. BM7 1992:304:393-4. (15 February.)

3 Strandberg TE, Salomaa V, Naukkarinen V, Vanhanen HT, Sarna SJ, Miettinen TA. Long term mortality after 5 year multifactorial primary prevention of cardiovascular diseases in multifactorial primary prevention of cardiog

4 Standing Medical Advisory Committee to the Department of

Health. Report on cholesterol testing. London: $\mathrm{DoH}, 1990$.

SIR, - The real issue with regard to cholesterol lowering drugs is appropriate use, or targeting. Al therapeutic interventions have some trade off zone where disadvantages offset any potential benefit. What is going badly wrong with cholesterol is that many patients with marginal excess concentrations, a low overall risk score, and little potential benefit are being prescribed drugs whereas other patients

- with high risk scores, including cholesterol concentrations often in genetic excess, are being neither treated nor even identified until some disaster strikes. Secondary prevention has a place, but many die before they can get it.

Overenthusiastic pharmaceutical promotion certainly has a role, but from the data cited by George Davey Smith and Juha Pekkanen around one in a 1000 of the British population are now taking lipid lowering drugs ${ }^{1}-$ hardly the therapeutic avalanche proposed and not even remotely 
encompassing the group genetically at high risk. Detailed analysis of individual deaths during treatment does not favour any severe risk, particularly of non-accidental violent death'; complete abolition of coronary heart disease would increase life expectancy by only three years, premature mortality and morbidity being the $\mathrm{key}^{\prime}$; and a naturally low cholesterol concentration may increase the risk of stroke while reducing the risk of coronary heart disease. It is all a question of balance.

It is a proper concern that treatment may on balance be harmful in some patients, although any mechanisms are wholly speculative, but we also know that the special minority do badly without treatment. At a meeting organised by the Royal Statistical Society recently Michael Oliver was emphatic that young, middle aged, or clinically affected men with cholesterol concentrations above $7.5 \mathrm{mmol} / \mathrm{l}$ were potential candidates for lipid lowering drugs (a lower intervention poin than many propose), endorsing the thrust if not the style of his editorial. ${ }^{+} \mathrm{A}$ blanket moratorium on treatment is nonsense, but we do need to sharpen up perceptions of when and when not to introduce lipid lowering as a part of a sensible treatment plan. TONY WINDER

Department of Chemical Pathology and Human Metabolism, Roval Free Hospital School of Medicine, London NW3 2QG

1 Davey Smith G, Pekkanen J. Should there be a moratorium on cholesterol lowering drugs? B.Mf 1992:304:431-4. (15 February.)

$2 W_{\text {ysowski DK, Gross TP. Deaths due to accidents and violence }}$ in two recent trials of cholesterol-lowering drugs. Arch Interm Med 1990;150:2169-72.

3 Tserat J, Weinstein MC, Williams LW, Tosteson ANA, Goldman L. Expected gains in life expectancy from variou Goldman L. Expected gains in life expectancy from various 1991;83:1194-201.

+ Oliver MF. Doubts about preventing coronary heart disease. B.HF 1992:304:393-4. (15 February.

SIR,--George Davey Smith and Juha Pekkanen inappropriately include the expanded clinical evaluation of lovastatin (EXCEL) study ${ }^{1}$ in their meta-analysis of cholesterol lowering interventions for primary prevention of coronary disease and misinterpret it to support their argument that cholesterol lowering treatment may not reduce mortality. " The objective of the EXCEL study was to evaluate the safety of the 3-hydroxy-3methylglutaryl coenzyme A reductase inhibitor lovastatin in a large trial. It was not designed to show primary prevention: the 48 weeks of treatment was much too short for this purpose, and $28 \%$ of the patients had known ischaemic heart disease at baseline. No study of primary or seondary prevention with a 3-hydroxy-3-methylglutaryl coenzyme A reductase inhibitor has yet been completed.

The EXCEL study randomised 8245 patients into five equal groups taking lovastatin $20 \mathrm{mg}$ daily, $40 \mathrm{mg}$ daily, $20 \mathrm{mg}$ twice daily, or $40 \mathrm{mg}$ twice daily, or placebo. There were nine, five, 10 , nine, and three deaths, respectively, in the five groups. These differences did not approach significance ( $p>0 \cdot 2$ by the Kaplan-Meier method). As the authors reported, of the 36 deaths, 31 were due to coronary disease, two to a pulmonary embolism after surgery, and one each to a ruptured aortic aneurysm, a haemorrhagic stroke, and viral pneumonia. Twenty five of these 36 patients had known ischaemic heart disease at baseline.

An adverse effect of lovastatin on coronary mortality is highly improbable for several reasons. Firstly, there was a trend towards fewer nonfatal myocardial infarctions in the groups given lovastatin (10, three, 13, 11 , and 18 patients, respectively). Secondly, lovastatin when given concomitantly with a bile acid sequestrant slows the progression and induces regression of atheromatous coronary lesions. 'Thirdly, as Davey Smith and Pekkanen's meta-analysis shows, there is good evidence that lipid lowering treatment reduces deaths from coronary heart disease.

A point more relevant to the issues that Davey Smith and Pekkanen raise is that no traumatic deaths occurred in the EXCEL study. The same is true for a five year study of lovastatin in 745 patients $^{3}$ (lovastatin study groups, unpublished results); and in a one year study in 2361 patients of the closely related simvastatin one accidental death occurred. These three studies together provide roughly 12000 patient years of vigorous lipid lowering treatment with only one death due to an accident and none due to suicide or homicide. Only the lovastatin five year study is long enough to be informative on the incidence of cancer, which was well below that expected on an actuarial basis (lovastatin study groups, unpublished results). Whatever the explanation for the differences in non-cardiac mortality reported in some of the studies of older drugs, there is no evidence that lovastatin or simvastatin has any effect on non-cardiac mortality.

J A TOBERT

Merck Sharp and Dohme Research Laboratorie

PO Box 2000

Rahway, New Jersey 07065-0900,

USA

I Bradford RH, Shear CL, Chremos AN, Dujovne C, Downton M Franklin FA, et al. Expanded clinical evaluation of lovastatin (EXCEL) study results. I. Efficacy in modifying plasm lipoproteins and adverse event profile in 8245 patients with moderate hypercholesterolemia. Arch Intern Med 1991;151:43-9.

Davey Smith G, Pekkanen J. Should there be a moratorium on the use of cholesterol lowering drugs? BMF 1992;304:431-4 (15 February.)

3 Brown G, Albers JJ, Fisher LD, Schaefer FM, Lin J, Kaplan C, et al. Regression of coronary artery disease as a result of et al. Regression of coronary artery disease as a result of
intensive lipid-lowering therapy in men with high levels of intensive lipid-lowering therapy in men with hig
apolipoprotein B. N Engl F Med 1990;323:1289-98.

+ Tobert JA. Cholesterol lowering and non-cardiac mortality. Lancet 1991;338:126.

5 Boccuzzi SJ, Bocanegra TS, Walker JF, Shapiro DR, Keegan ME. Long-term safety and efficacy profile of simvastatin Am f Cardiol 1991;68:1127-31.

\section{Managing hypertension}

SIR,-We were interested in the results of the Medical Research Council's trial of treatment of hypertension in older adults and their implications for the treatment of hypertensive patients of all ages, particularly the prevention of stroke. Individual studies and meta-analyses show that about $40 \%$ of stroke in hypertensive patients can be prevented by drug treatment. ${ }^{2}$

In the Western Infirmary we recently established an acute stroke unit, which admits around 300 unselected patients each year from a catchment population of 220000 . Blood pressure immediately after stroke may increase temporarily. We have information on previous diagnosis and treatment for 351 patients (159 men (median age 67) and 192 women (median age 74$)$ ). Of these, 117 were aged $70-79$ and 80 were aged $\geqslant 80$. Hypertension had been diagnosed in 132 patients (information obtained from the patient, relatives, or general practitioner's referral letter), but only 62 were receiving drug treatment: $12(44 \%)$ of the 27 aged $\geqslant 80,23(49 \%)$ of the 47 aged $70-79$, and 27 $(47 \%)$ of the 58 aged $<70$. Thirty seven $(60 \%)$ of the 62 receiving treatment for hypertension had at least one other major cardiovascular risk factor, as did $30(43 \%)$ of the 70 not receiving treatment.

We do not know why antihypertensive treatment was not offered to or continued in patients at high risk of stroke and vascular disease. Some of the patients had been treated previously but had either stopped taking their drugs or had their treatment stopped weeks or months before presenting with stroke. Despite the clear evidence of the value of antihypertensive treatment in younger patients that has been available for many years it is surpris ing that the "rule of halves" still holds: up to half of all hypertension is unrecognised and only half of detected hypertension is treated. It remains to be seen whether further evidence of the benefits of treating elderly hypertensive patients will influence medical practice. If it does not many strokes that are preventable will occur, with resultant disability and death.

\section{KENNEDY R LEES GORDON T MCINNES}

JOHN L REID

IAIN B SQUIRE

Department of Medicine and Therapeutics,

University of Glasgow,

Gardiner Institute,

Glasgow Gil 6NT

1 MRC Working Party. Medical Research Council trial of treatment of hypertension in older adults: principal results. $B M \mathcal{Y}$ 1992;304:405-12. (15 February.)

2 Beard K, Bulpitt C, Mascie-Taylor H, O'Malley K, Severe P, Webb S. Management of elderly patients with sustained Webb S. Management of elderly patients with
hypertension. BMf 1992;304:412-6. (15 February.)

3 Collins R, Peto R, MacMahon S, Hebert P, Fiebach NH, Eberlein KA, et al. Blood pressure, stroke, and coronary hear disease. Part 2. Short term reductions in blood pressure: overview of randomised drug trials in their epidemiologica context. Lancet 1990;335:827-38.

\section{Thrombosis and pulmonary embolism}

SIR, - In their article on thrombosis and pulmonary embolism N F G Hopkins and John H N Wolfe describe chest radiographic findings in pulmonary embolism without making it clear that, in most cases, there is either no abnormality or minimal, non-specific change in the plain chest film.

In their discussion of ventilation-perfusion lung scans they do not mention that scans are classified as showing a normal or very low, a low, an intermediate or indeterminate, or a high probability of embolism. Though the first and last of these groups can be taken at face value (although even they are not $100 \%$ guarantees), patients with scans showing a low probability were shown by the prospective investigation of pulmonary embolism diagnosis to have a $14 \%$ incidence of embolism. ${ }^{2}$ Either one has to do pulmonary arteriography on, at least, all patients with scans showing an indeterminate probability or one adopts the policy that in the absence of a scan showing a high probability and of persisting venous thrombosis (diagnosed by whatever means) pulmonary embolism, even if present, does not require treatment. One cannot, however, just take ventilationperfusion scanning as a test that will in every case tell for certain whether pulmonary embolism is present.

With respect to the investigation of deep venous thrombosis, as stated venography remains the standard test. Ultrasound can be used in severa ways. Duplex Doppler ultrasonography will show venous patency accurately from the poplitea vein up, and the use of colour flow even allows assessment in the calf and will show non-occlusive thrombus. Without Doppler, however, ultrasound relies on the compression method. At best this is of use only in the groin and upper thigh and in the popliteal fossa (the vein being too deep in the adductor canal), and even in the groin noncompressibility can be normal where the long saphenous vein enters the femoral vein.

Radioisotope studies such as those using labelled fibrinogen or plasmin show only forming thrombus, not that already present. Hence anticoagulant treatment cannot be started until imaging is complete. Labelled antifibrin monoclonal antibodies will, however, target formed thrombus. Another method, not referred to in the article, is light reflective rheography. Though this is nonspecific (a positive result indicating venous abnormality but not necessarily thrombus), it is highly sensitive and could serve as a screening test to 